\title{
Mechanisms, continental approaches, trials, and evolutionary medicine: New work in the philosophy of medicine
}

\author{
Julian Reiss • Miriam Solomon • David Teira
}

Published online: 5 January 2011

(C) The Author(s) 2011. This article is published with open access at Springerlink.com

Keywords Philosophy of Medicine - Mechanisms · Outcome measures · Classification $\cdot$ Stop rule $\cdot$ Phenomenology $\cdot$ Evolutionary medicine

The Philosophy of Medicine Roundtable was created in order to promote epistemological and ontological inquiry in medicine. Ethical questions about medicine have received plentiful attention in the last 40 years, with societies, journals, and meetings devoted to bioethics and health care ethics. Epistemological and ontological questions about medicine have, until recently, only sporadically attracted interest from philosophers of science. Notable landmarks include works by Christopher Boorse [1], George Engel [2], Ronald Munson [3], Kenneth Schaffner [4], Paul Thagard [5], Kay Toombs [6], Scott Sehon and Donald Stanley [7], Richard Ashcroft [8], Aaron Cohen et al. [9], and John Worrall [10]. Topics of concern include the definitions of diseases and health, the hierarchy of evidence in evidence-based medicine, the nature of causality in medicine, and the challenges to traditional biomedicine posed by narrative and phenomenological approaches. In the last 6 years, interest in philosophy of medicine has greatly increased, with several conferences, special journal issues, and edited anthologies on these topics. Analytic and continental approaches to philosophy are both represented.

\footnotetext{
J. Reiss $(\square)$

Faculty of Philosophy, Erasmus University, P.O. Box 1738, 3000 DR Rotterdam, The Netherlands e-mail: reiss@fwb.eur.nl
}

\section{Solomon}

Philosophy Department, Temple University, 022-32, Philadelphia, PA 19122, USA

D. Teira

Department of Logic, History and Philosophy of Science, UNED Humanidades,

Paseo de Senda del rey 7, 28040 Madrid, Spain 
The Philosophy of Medicine Roundtable is one of these new initiatives. It was begun by Harold Kincaid at the Department of Philosophy of the University of Alabama, Birmingham, who hosted Philosophy of Medicine Roundtables in 2004 (27 papers), 2005 (13 papers), and 2008 (19 papers). All of them were sponsored by the UAB Center for Ethics and Values in the Sciences. From the 2004 conference came the 2007 volume Establishing Medical Reality: Essays in the Metaphysics and Epistemology of Biomedical Science [11].

European philosophers of medicine always had strong representation at the University of Alabama at Birmingham meetings, and our next step was to hold a Roundtable in Europe. Thanks to the hospitality of Erasmus University Rotterdam and the Erasmus Institute for Philosophy and Economics, the first European Roundtable took place in Rotterdam, the Netherlands, in October 2009. Julian Reiss raised the funds, took care of local arrangements, and, together with Harold Kincaid, Miriam Solomon, and David Teira, organized the program. There were four invited lectures by Raffaella Campaner, Fred Gifford, Daniel Hausman, and Jan Vandenbroucke and 14 additional presentations (out of a total of 30 submitted abstracts). The next Philosophy of Medicine Roundtable is planned for sometime in 2011 or 2012. Jeremy Simon maintains an email list of over a hundred scholars interested in philosophy of medicine, and a website for the Philosophy of Medicine Roundtable (http://philosmed.org) is currently being constructed.

Other recent initiatives in philosophy of medicine include the highly successful Progress in Medicine conference that was held at Bristol University in April 2010 and the forthcoming 16th volume of the Elsevier Handbook of Philosophy of Science, which is being edited by Fred Gifford under the title Philosophy of Medicine. Robyn Bluhm, Kirstin Borgerson, and Maya Goldenberg have also edited two special issues of Perspectives in Biology and Medicine in 2005 and 2009 on evidence-based medicine. And several contributed sessions on these topics were held at recent conferences of the Philosophy of Science Association and the Society for Philosophy of Science in Practice.

This compilation presents a sample of the papers presented in Rotterdam. Space in the journal was limited, but we hope that the selection will give at least a glimpse of some of the debates being conducted. We have selected two papers on causal mechanisms (a currently popular topic in analytic philosophy of science), two papers on Continental philosophical approaches to understanding patient experience, one paper on decision making in clinical trials, and one paper on the idea of 'evolutionary medicine'.

In 'Understanding Mechanisms in the Health Sciences', Raffaella Campaner analyses how causal mechanisms are hypothesized and tested in biomedical research. There is a growing literature on mechanisms in different scientific fields that Campaner assesses for applicability to medicine. She pays particular attention to the Russo-Williamson thesis, according to which one should take into account both mechanistic and probabilistic evidence in order to assess causal claims. Campaner argues that it is important to distinguish between 'evidence on mechanisms that have already been disclosed, and evidence for mechanisms that are currently unknown and to be discovered'. Evidence of the latter type is provided by interventions designed to test the existence of hypothesised mechanisms. 
We currently do not have agreed upon guidelines for such interventions in biomedical research, but, Campaner contends, they are called for and philosophers of medicine should address them.

Brendan Clarke's 'Causation and Melanoma Classification' is a discussion of the consequences of our greater understanding of the aetiology of melanomas. Particular genetic mutations that lead to melanomas (e.g., c-KIT and BRAF) can now be identified, and it turns out that these mutations are more useful for prognosis and treatment decisions than the traditional classification of melanomas in terms of their morphology or site on the body. Clarke concludes that melanoma classification should be based on the genetic aetiology of the tumour, interpreting it as a mechanistic process as understood by Machamer, Darden, and Craver [12]. According to this approach, causal interventions on tumours reveal 'features that are stable across a range of background conditions' and thereby are amenable to therapeutic intervention.

Two papers make use of methodologies from continental philosophy to describe patient experience. Havi Carel uses a phenomenological approach inspired by Merleau-Ponty and Heidegger to show the incompleteness of standard biomedical descriptions, and Leah McClimans and John Browne use hermeneutical considerations from Hans-Georg Gadamer to challenge the possibility of standardization of patient-reported outcome measures.

Carel argues that the phenomenology of the body in illness provides information that is relevant to medical care. She develops some ideas from her recent book Illness: The Cry of the Flesh [13] to create general epistemic tools for medical training and clinical practice. She contends that we should take into account the first person experience of the body, including its nonverbal manifestations (e.g., bodily movement and gestures) in order to define illness. So-called 'objective measurements' of well-being often do not correlate with phenomenological experiences, and Carel argues that the phenomenological experiences should sometimes take priority. Carel finds that phenomenological descriptions are helpful for addressing ethical as well as medical questions about patient care.

McClimans and Browne take a look at patient-reported outcome measures (PROMs). These are questionnaires that assess patients' perceived quality of life or perceived health status after a medical intervention. PROMs are increasingly preferred for health technology evaluations. However, there is no standard form that a PROM takes. McClimans and Browne's paper, 'Choosing a Patient-Reported Outcome Measure', suggests that the meaning of a patient's report should be interpreted according to the principles of Gadamerian hermeneutics. Instead of a fixed and definite content, these responses are only interpretable in the context of a particular understanding of the question and its circumstances. Nevertheless, the authors insist on traditional standards for all PROMs: reliability (the consistency of a measure) and validity (the extent to which a measure addresses the correct construct). However, the authors argue that it is a matter of judgment when determining which evidence is relevant for assessing any of these two properties. Moreover, such judgments cannot be made a priori but require domain knowledge.

In 'Statistical Decisions and the Interim Analyses of Clinical Trials', Roger Stanev analyses what he calls 'hard-case clinical trials': medical experiments in 
which 'the severity of the condition being treated is high, the availability of alternative treatments is lacking, or uncertainty about the clinical importance of observed differences between treatments persists'. In such cases, there may be ethical reasons to stop the trial earlier than planned. When facing such situations, data monitoring committees have to make difficult choices, articulating ethical and scientific principles into statistical decision rules. Stanev puts forward a very detailed decision analytic framework for comparing these rules, which yields a clearer understanding of the decision processes in hard-case clinical trials.

Finally, Pierre-Olivier Méthot surveys the 'Research Traditions and Evolutionary Explanations in Medicine', illustrating their differences with an analysis of disease. Méthot claims that a distinction should be made between a specific 'Darwinian medicine' and a more general 'evolutionary medicine' regarding their respective approaches to explanation. Darwinian medicine constructs 'backward looking' explanations, where adaptive explanations are sought for particular diseases in the context of the environmental and social conditions of the Pleistocene era. Evolutionary medicine adopts a broader and more 'forward looking' approach in which explanations try 'to predict the effects of ongoing evolutionary processes on human health and disease in contemporary environments (e.g., hospitals)'. Méthot explores at length the scope and practical implications of each of these two research agendas.

Open Access This article is distributed under the terms of the Creative Commons Attribution Noncommercial License which permits any noncommercial use, distribution, and reproduction in any medium, provided the original author(s) and source are credited.

\section{References}

1. Boorse, C. 1977. Health as a theoretical concept. Philosophy of Science 44(4): 542-573.

2. Engel, G.L. 1977. The need for a new medical model. Science 196(4286): 129-136.

3. Munson, R. 1981. Why medicine cannot be a science. Journal of Medicine and Philosophy 6: 183-208.

4. Schaffner, K.F. 1985. Logic of discovery and diagnosis in medicine. Berkeley: University of California Press.

5. Thagard, P. 1999. How scientists explain disease. Princeton: Princeton University Press.

6. Toombs, S.K. 2001. Handbook of phenomenology and medicine. Dordrecht: Kluwer Academic.

7. Sehon, S.R., and D.E. Stanley. 2003. A philosophical analysis of the evidence-based medicine debate. BMC Health Services Research 3(1):14-23.

8. Ashcroft, R.E. 2004. Current epistemological problems in evidence based medicine. Journal of Medical Ethics 30(2): 131-135.

9. Cohen, A.M., P.S. Stavri, and W.R. Hersh. 2004. A categorization and analysis of the criticisms of evidence-based medicine. International Journal of Medical Informatics 73(1): 35-43.

10. Worrall, J. 2007. Evidence in medicine and evidence-based medicine. Philosophy Compass 2(6): 981-1022.

11. Kincaid, H., and J. McKitrick, eds. 2007. Establishing medical reality: Essays in the metaphysics and epistemology of biomedical science. Dordrecht: Springer.

12. Machamer, P., L. Darden, and C.F. Craver. 2000. Thinking about mechanisms. Philosophy of Science 67(1): 1-25.

13. Carel, H. 2008. Illness: The cry of the flesh. Art of Living Series. Stocksfield: Acumen. 